\title{
Symptomatic gastro-oesophageal reflux, abnormal oesophageal acid exposure, and mucosal acid sensitivity are three separate, though related, aspects of gastro-oesophageal reflux disease
}

\author{
P J Howard, L Maher, A Pryde, R C Heading
}

\begin{abstract}
The Bernstein test has been used as a test of oesophageal acid sensitivity for over $\mathbf{3 0}$ years but its clinical value has been challenged by the advent of ambulatory pH monitoring. Furthermore, the relation between mucosal acid sensitivity, symptomatic reflux, and abnormal oesophageal acid exposure time is unclear. This study examined the relation between these three parameters in patients referred for pH monitoring with unexplained chest pain or heartburn. Fifty consecutive patients were studied - nine with non-cardiac chest pain and 41 with a history of heartburn. Symptomatic reflux was defined as $a \geqslant 50 \%$ temporal association between pain episodes and reflux events (pH <4) during $\mathrm{pH}$ monitoring. A positive acid perfusion test (in which the patient's usual symptoms were evoked by acid, though not saline) had a $100 \%$ sensitivity, $73 \%$ specificity, and $81 \%$ accuracy for the detection of symptomatic reflux. All 10 patients with symptomatic reflux during $\mathrm{pH}$ monitoring had evidence of mucosal acid sensitivity. A negative acid perfusion test made symptomatic reflux unlikely. However, symptomatic reflux or a positive acid perfusion test, or both, were found in some patients with a normal oesophageal acid exposure time during $\mathrm{pH}$ monitoring. Mucosal acid sensitivity, abnormal oesophageal acid exposure time, and symptomatic reflux should be regarded as separate, though related aspects of reflux disease. The Bernstein test is simple, safe, and easily performed. A positive test helps to identify an oesophageal cause of symptoms, particularly in patients in whom other aspects of 'gastro-oesophageal reflux disease' are absent, or who do not have symptoms during $\mathrm{pH}$ monitoring.
\end{abstract}

Department of Medicine, Royal Infirmary, Edinburgh P J Howard L Maher A Pryde

R C Heading

Correspondence to: Dr P J Howard, Department of Medicine, Royal Infirmary of Edinburgh, Lauriston
Place, Edinburgh EH3 9YW. Accepted for publication 23 April 1990
The Bernstein test has been in clinical use for over 30 years as a means of reproducing oesophageal pain.' It was originally designed as a test of oesophageal acid sensitivity. It has also been used more recently as a provocative test during oesophageal manometry in patients with noncardiac chest pain. ${ }^{2+}$ Nevertheless, the role of acid perfusion in the elucidation of oesophageal pain has been challenged by the advent of ambulatory $\mathrm{pH}$ monitoring. ${ }^{5}$
It is now recognised that so-called gastrooesophageal reflux disease arises when gastric refluxate causes symptoms or oesophageal mucosal damage, or both. Current diagnostic tests evaluate four aspects of reflux disease - the amount of gastro-oesophageal reflux, reflux symptoms, mucosal acid sensitivity, and the presence of mucosal damage. There are now many publications reporting the sensitivities and specificities of the various tests for the diagnosis of reflux disease..$^{5-1+}$ Nevertheless, many investigators have recognised that varying definitions of reflux disease and the lack of any absolute standard against which the diagnostic tests may be compared render these sensitivity and specificity calculations of doubtful value. In fact, no test available at present can be expected to serve as a gold standard for oesophageal reflux disease, because the disease itself is not a single entity. There has been longstanding recognition that not all patients with oesophagitis have reflux symptoms and not all patients with reflux symptoms have oesophagitis. Consequently, there should be no surprise or disappointment when carefully performed tests of different facets of reflux disease fail to produce agreement. For example, a negative acid perfusion test in a patient with oesophagitis should not be viewed as a false negative result ${ }^{12}$ - it is no more than a demonstration that acid sensitivity is absent in that patient. Symptomatic gastro-oesophageal reflux, mucosal acid sensitivity, and abnormal oesophageal exposure to acid are all distinct aspects of gastro-oesophageal reflux disease. The aim of this study was to examine the relations between them in patients referred for investigation of non-cardiac chest pain or heartburn.

\section{Methods}

Fifty consecutive patients referred with either non-cardiac chest pain (four men and five women; mean (SD) age 43.2 (12.9) years) or suspected gastro-oesophageal reflux (26 men and 15 women; mean (SD) age $43.2(11 \cdot 3)$ years) were studied. They had all undergone endoscopy before referral. Of the 41 patients referred because of suspected reflux symptoms, two had a Barrett's oesophagus and six had oesophagitis. All nine patients with non-cardiac chest pain had a normal endoscopy appearance. Myocardial 
ischaemia was excluded by exercise cardiography and coronary arteriography, as appropriate.

\section{ACID PERFUSION TEST}

The acid perfusion test was performed after routine oesophageal manometry. Physiological saline was infused into the oesophagus $7 \mathrm{~cm}$ from the lower oesophageal sphincter via an Arndorfer catheter at a rate of $6 \mathrm{ml} /$ minute for seven minutes. If no symptoms were produced, the infusion rate was increased to $14 \mathrm{ml} /$ minute for a further eight minutes by infusing saline at $8 \mathrm{ml} / \mathrm{minute}$ through a second port within the proximal oesophagus at approximately $22 \mathrm{~cm}$ from the lower sphincter. Next, the infusion was changed without the patient's knowledge to $0 \cdot 1 \mathrm{~N} \mathrm{HCl}$ at $6 \mathrm{ml} /$ minute for seven minutes, and at $14 \mathrm{ml} /$ minute for a further eight minutes if no symptoms were evoked. The test was regarded as positive if infusion of acid, but not saline, reproduced the patient's usual chest pain, discomfort, or heartburn. Electrocardiography was performed if symptoms were produced either with saline or acid, or at the completion of the acid infusion, if symptoms were not elicited.

\section{TWENTY THREE HOUR PH MONITORING}

Twenty three hour $\mathrm{pH}$ monitoring was performed using a combined glass $\mathrm{pH}$ electrode with an internal reference electrode (Radiometer, Copenhagen) which was calibrated against two buffers at $\mathrm{pH} 4$ and 7 before each study. The $\mathrm{pH}$ probe was passed through the nose and positioned $3 \mathrm{~cm}$ above the upper border of the manometrically defined lower oesophageal sphincter. Output from the electrode was recorded onto a battery driven (microchip) recorder.

Ambulatory $\mathrm{pH}$ monitoring was performed on an outpatient basis after stopping all medication for at least 48 hours. No restrictions were placed on patients' activities, eating, drinking, or smoking habits. Each patient was provided with a digital watch and a diary card on which to record the time of eating, drinking, and changes of posture and the time of onset of their symptoms. Symptoms were defined as reflux related if their onset was reported during, or up to five minutes after, a reflux episode. (A reflux episode was defined as the time during which $\mathrm{pH}$ fell below 4 until it rose again above $\mathrm{pH} 4$ ).

The $\mathrm{pH}$ recordings were analysed by an Apple II computer which measured the distal oesophageal acid exposure times, expressed as a percentage of recording time. A total acid exposure time of $>7 \%$ recording time is taken as abnormal in our laboratory. Our normal range is based upon $\mathrm{pH}$ monitoring in 34 healthy control subjects, performed under identical conditions to those of the present study. ${ }^{15}$

\section{DATA ANALYSIS}

\section{Ambulatory $p H$ recordings}

A symptom-reflux association was defined as the percentage of pain (or heartburn) episodes that occurred during, or up to five minutes after, a reflux event. 'Symptomatic gastro-oesophageal reflux' was taken as a $50 \%$, or greater, association between pain episodes and reflux events.

Comparisons between acid perfusion test, symptomatic reflux, and abnormal acid exposure time

Ambulatory $\mathrm{pH}$ monitoring was used to measure distal oesophageal acid exposure time and to identify patients with symptomatic reflux. The acid perfusion test defined patients with oesophageal acid sensitivity. The sensitivity, specificity, positive and negative predictive values, and accuracy of each of these parameters were calculated, taking each of the other two as arbitrary gold standards. For example, the sensitivity and specificity of oesophageal acid sensitivity (positive acid perfusion test) as a test for symptomatic reflux and abnormal acid exposure time were calculated. Since sensitivity and specificity are related to disease prevalence, however, the positive and negative likelihood ratios were also calculated. The positive and negative likelihood ratios are estimates of the discriminatory power of a test and are independent of disease prevalence. ${ }^{16}{ }^{17}$ Hence, the higher the positive likelihood ratio the greater the odds in favour of disease if the test is positive. Conversely, the greater the negative likelihood ratio the greater are the odds against disease if the test is negative. In order to clarify the interrelations between acid sensitivity, symptomatic reflux, and abnormal acid exposure time, Venn diagrams were used to express the data for two threshold values of symptom-reflux association $50 \%$ (used to define symptomatic reflux in this paper) and $25 \%$ as suggested by Hewson et al. ${ }^{5}$

\section{Results}

\section{REPORTING OF SYMPTOMS}

Two of the 50 patients reported their symptoms as being constantly present during $\mathrm{pH}$ monitoring and one patient failed to record the timing of symptoms. Therefore, symptomatic reflux could only be assessed in 47 patients (nine with noncardiac chest pain and 38 with suspected reflux).

The patients' usual pain or heartburn was reported by six of the nine patients with noncardiac chest pain and 26 of 38 patients who presented with possible reflux symptoms during ambulatory $\mathrm{pH}$ monitoring. The median number of reported pain episodes in both the patients with non-cardiac chest pain and suspected reflux was 2 with ranges of 0 to 20 and 0 to

TABLE I Overall results of acid perfusion test $(A P T)$ and $p H$ monitoring in 50 consecutive patients

\begin{tabular}{|c|c|c|c|c|}
\hline \multirow[b]{2}{*}{ Test results } & \multicolumn{4}{|c|}{ ph Monitoring } \\
\hline & $\begin{array}{l}S R A \\
>50 \%\end{array}$ & $\begin{array}{l}S R A \\
<50 \%\end{array}$ & $\begin{array}{l}\text { No pain } \\
\text { reported }\end{array}$ & $\begin{array}{l}\text { Reporting } \\
\text { uninter- } \\
\text { pretable }\end{array}$ \\
\hline \multicolumn{5}{|l|}{ APT + ve: } \\
\hline Normal reflux & 5 & 5 & 2 & 1 \\
\hline Abnormal reflux & 5 & 1 & 2 & 0 \\
\hline \multicolumn{5}{|l|}{ APT - ve: } \\
\hline Normal reflux & $\begin{array}{l}0 \\
0\end{array}$ & 13 & 6 & 1 \\
\hline Abnormal reflux & 0 & 3 & 5 & 1 \\
\hline
\end{tabular}




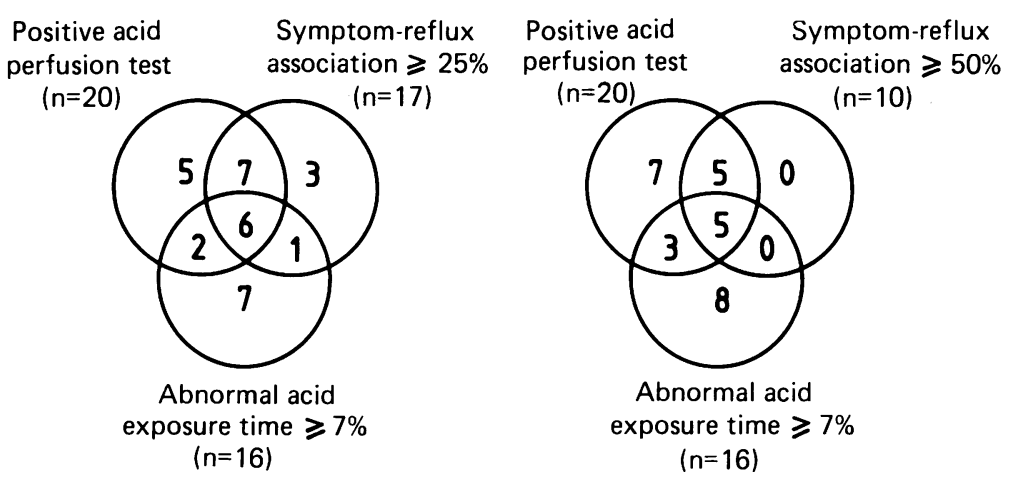

Relation between a positive acid perfusion test ( $A P T)$, abnormal acid exposure time (AET), and symptomatic reflux (defined as a symptom-reflux association of $>25 \%$ and $<50 \%$. Not all the patients experienced pain during $p H$ monitoring. Considering the left hand Venn diagram, 2 of 5 patients with +ve APT alone, 5 of 7 with abnormal reflux alone, and both those with abnormal $A E T$ and +ve APT did not experience pain.

In the right hand Venn diagram, the corresponding numbers of patients without pain during the $\mathrm{pH}$ study were 2 of 7,5 of 8 , and 2 of 3.

11 , respectively. None of the patients with noncardiac chest pain complained of heartburn during $\mathrm{pH}$ monitoring or acid perfusion. Therefore data relating to symptomatic reflux and positive acid perfusion test results refer to the patients' usual symptoms in all cases. Two of the nine patients with non-cardiac chest pain experienced their usual pain during the acid perfusion test and both had symptomatic reflux on $\mathrm{pH}$ monitoring. Of the 38 patients with suspected reflux symptoms, 19 had their symptoms reproduced by acid perfusion (positive acid perfusion test) and eight of these had symptomatic reflux. There were no electrocardiographic changes during acid perfusion.
INTER-RELATIONS BETWEEN ACID SENSITIVITY, SYMPTOMATIC REFLUX, AND ABNORMAL OESOPHAGEAL ACID EXPOSURE TIME

The overall results in the 50 patients are shown in Table I. The inter-relations between symptomreflux association, acid exposure time, and a positive acid perfusion test are shown in the Figure $(n=47)$. Table II shows the sensitivities,

TABLE II Relations between abnormal acid exposure time ( $>7.0 \%$ recording time), oesophageal acid sensitivity (+ve acid perfusion test), and symptomatic reflux (symptom-reflux association $>50 \%$ ). The sensitivities, specificities, positive and negative predictive values, and likelihood ratios have been calculated for each of the three parameters using the other two as arbitrary gold standards

\begin{tabular}{|c|c|c|c|}
\hline & $\begin{array}{l}\text { Abnormal acid } \\
\text { exposure time }\end{array}$ & $\begin{array}{l}\text { Oesophageal acid } \\
\text { sensitivity }\end{array}$ & $\begin{array}{l}\text { Symptomatic } \\
\text { reflux }\end{array}$ \\
\hline \multicolumn{4}{|c|}{ Oesophageal acid sensitivity: } \\
\hline SENS $(\%)$ & 40 & - & 100 \\
\hline SPEC (\%) & 70 & - & 73 \\
\hline PPV (\%) & 50 & - & 62 \\
\hline NPV (\%) & 61 & - & 100 \\
\hline PLR & $1 \cdot 35$ & - & 3.67 \\
\hline NLR & 0.85 & - & 0.00 \\
\hline ACC (\%) & 57 & - & 81 \\
\hline \multicolumn{4}{|c|}{ Symptomatic reflux: } \\
\hline SENS (\%) & 55 & 62 & - \\
\hline SPEC $(\%)$ & 78 & 100 & - \\
\hline PPV (\%) & 50 & 100 & - \\
\hline NPV $(\%)$ & 82 & 73 & - \\
\hline PLR & $2 \cdot 50$ & - & - \\
\hline NLR & 0.57 & 0.38 & - \\
\hline ACC (\%) & 72 & 82 & - \\
\hline \multicolumn{4}{|c|}{ Abnormal acid exposure time: } \\
\hline SENS (\%) & - & 40 & 50 \\
\hline SPEC (\%) & - & 70 & 82 \\
\hline PPV (\%) & - & 50 & 55 \\
\hline NPV (\%) & - & 61 & 78 \\
\hline PLR & - & $1 \cdot 35$ & $2 \cdot 75$ \\
\hline NLR & - & 0.85 & 0.61 \\
\hline ACC (\%) & - & 57 & 72 \\
\hline
\end{tabular}

SENS = Sensitivity SPEC $=$ specificity PPV $=$ positive predictive value; $N P V=$ negative predictive value; $P L R=$ positive likelihood ratio; NLR = negative likelihood value; $A C C=$ accuracy. specificities, positive predictive value, negative predictive value, and likelihood ratios calculated for each of the three parameters using the other two as gold standards, based upon the data in Table I.

The inter-relations between the three parameters are perhaps best understood by reference to the Figure. Using our definition of symptomatic reflux (symptom-reflux association $>50 \%$ ), it can be seen that all 10 patients with symptomatic reflux had an acid sensitive oesophagus and five of these had an abnormal acid exposure time. Ten of 20 patients with a positive acid perfusion test, however, did not have symptomatic reflux on $\mathrm{pH}$ monitoring. However, of these 10 positive patients, four did not experience symptoms during $\mathrm{pH}$ monitoring. Hence, while symptomatic reflux occurred only in those with acid sensitivity, acid sensitivity was not specific for symptomatic reflux. Eight of 16 patients with abnormal acid exposures had neither acid sensitivity nor symptomatic reflux. (However, five of these eight patients had no pain during ambulatory $\mathrm{pH}$ monitoring.) Therefore, all the patients with symptomatic reflux had acid sensitivity and $50 \%$ had abnormal acid exposure. Conversely, $50 \%$ of those with a positive acid perfusion test had symptomatic reflux $(62 \%$ considering only those with pain during $\mathrm{pH}$ monitoring). Half of the patients with abnormal acid exposure had neither acid sensitivity nor symptomatic reflux. (The corresponding figure was $33 \%$ of patients who experienced pain during $\mathrm{pH}$ monitoring.) When the data were analysed using a lower threshold to define symptomatic reflux, as suggested by Hewson et $a l,{ }^{5}$ the same overall pattern emerged. The number of patients with symptomatic reflux increased from 10 to 17 , as expected. Thirteen of 20 patients with acid sensitivity had symptomatic reflux on $\mathrm{pH}$ monitoring (13 of 16 considering only those with pain during $\mathrm{pH}$ monitoring). With a symptom-reflux association of $>25 \%, 44 \%$ of patients with an abnormal acid exposure time had neither reflux related symptoms nor acid sensitivity (33\% after excluding those without pain during $\mathrm{pH}$ monitoring).

Table II expresses the relations between symptom-reflux association, acid exposure time, and acid perfusion test numerically. Oesophageal acid sensitivity (positive acid perfusion test) is predictive of symptomatic reflux (sensitivity $100 \%$, specificity $73 \%$, and accuracy of $81 \%$ ). It is also a good discriminatory test for symptomatic reflux (positive likelihood ratio $3 \cdot 67$ ). Abnormal acid exposure did not, however, identify patients with either oesophageal acid sensitivity or symptomatic reflux.

\section{Discussion}

Gastro-oesophageal reflux disease encompasses a spectrum of disorders in which gastric refluxate causes symptoms or damage to the oesophageal mucosa, or both. Although the term gastrooesophageal reflux disease has been variously used to describe reflux oesophagitis, refluxrelated symptoms, abnormal oesophageal acid exposure, and mucosal acid sensitivity, it is becoming clear that these four aspects of reflux 
disease should be regarded as separate, though related entities.

The classic symptoms of gastro-oesophageal reflux are heartburn and acid regurgitation. ${ }^{18}$ Patients with reflux disease do not invariably present with typical symptoms, however, and a confident clinical diagnosis is not always possible on the basis of the history alone. Palmer ${ }^{19}$ found that only $4 \cdot 1 \%$ of 413 patients with oesophagitis complained of classic reflux symptoms while an additional $14 \cdot 3 \%$ had subxiphoid pain, $18 \cdot 1 \%$ had dysphagia, and $9 \cdot 4 \%$ had dyspepsia. Hence, less than half the patients with oesophagitis had symptoms possibly attributable to reflux. We have previously shown that only $60 \%$ of patients with oesophagitis had heartburn, regurgitation, or retrosternal chest pain as major presenting complaints. ${ }^{20}$ Similar difficulties in diagnosing reflux disease on the basis of the history were encountered by Wienbeck and Berges. ${ }^{18}$ In the present study, $84 \%$ of patients had an endoscopically normal oesophagus at the time of referral for ambulatory $\mathrm{pH}$ studies. Conversely, the proportion of patients thought to have reflux symptoms who have endoscopic evidence of oesophagitis varies from $40 \%$ to $80 \%$ in published series. ${ }^{21-24}$

The relation between reflux symptoms and abnormal acid exposure also raises further difficulties. We ${ }^{25}$ and others ${ }^{5}$ have recently shown that reflux symptoms can occur in some patients with normal oesophageal acid exposure times.

We therefore examined the relation between mucosal acid sensitivity, as determined by the acid perfusion test, and both distal oesophageal acid exposure time and symptomatic reflux during ambulatory $\mathrm{pH}$ monitoring in patients referred for ambulatory $\mathrm{pH}$ studies. Of course, this group is probably not representative of reflux patients as a whole. Nevertheless, patients requiring $\mathrm{pH}$ monitoring for the diagnosis of their symptoms constitute a clinically important group. We defined 'symptomatic reflux' as a $50 \%$, or greater, association between the patient's usual symptoms of chest pain or heartburn and reflux events. Since there is some disagreement as to threshold value for this temporal association we also used a threshold symptom - reflux association of $25 \%$ as recommended by Hewson et al. The present study confirms that abnormal acid exposure has a low predictive value for both oesophageal acid sensitivity and symptomatic reflux during $\mathrm{pH}$ monitoring, as we defined it. All the patients with symptomatic reflux, however, had evidence of mucosal acid sensitivity during acid perfusion when we used a symptom-reflux association of $50 \%$. (However, four of 17 patients with a symptom-reflux association of $>25 \%$ did not have acid sensitivity.) Therefore, in this group of patients, symptomatic reflux can be explained on the basis of mucosal sensitivity to acid using a threshold symptom-reflux association of $50 \%$, though not of $25 \%$. Conversely, a negative acid perfusion test makes symptomatic reflux (symptom-reflux association $>50 \%$ ) unlikely as no patient with a negative test had symptomatic reflux during $\mathrm{pH}$ monitoring. There were, however, patients with acid sensitivity who did not have symptomatic reflux on subsequent $\mathrm{pH}$ monitoring, even though acid infusion reproduced their usual symptoms. This confirms our previous studies ${ }^{3}$ and those of Janssens et al.$^{26} \mathrm{~A}$ possible explanation is that these patients have an 'irritable' oesophagus ${ }^{27}{ }^{28}$ which can respond to different stimuli by producing the same pattern of symptoms. Experimental support for the concept of the irritable oesophagus comes from the work of Peters $e t a l^{29}$ who showed that during combined ambulatory $\mathrm{pH}$ and pressure recordings some patients experienced identical symptoms during episodes of either dysmotility, gastro-oesophageal reflux, or both. Heartburn may also occur during belching even when it is not associated with reflux - presumably as a result of acute gaseous distension of the oesophagus. ${ }^{30}$

In conclusion, the acid perfusion test is safe, simple to perform, and does not require expensive equipment. After 30 years of clinical use, it remains a useful test for elucidating oesophageal chest pain, particularly in patients who do not experience symptoms during prolonged $\mathrm{pH}$ monitoring or who have atypical presentations, lack endoscopic evidence of oesophagitis, or have normal acid exposure times. Oesophagitis, abnormal acid exposure, mucosal acid sensitivity, and symptomatic reflux as defined by the temporal relation between symptoms and reflux events, should be regarded as separate, though related, aspects of gastro-oesophageal reflux disease. Identity of results from the various tests of reflux disease should neither be expected nor sought.

1 Bernstein LM, Baker LA. A Clinical test for esophagitis. Gastroenterology 1958: 34: 760-81.

2 De Caestecker JS, Blackwell JN, Brown J, Heading RC. The oesophagus as a cause of recurrent chest pain: which patients should be investigated and which tests used? Lancet 1985; ii: $1143-6$

3 De Caestecker JS, Pryde A, Heading RC. Comparison of intravenous edrophonium and oesophageal acid perfusion during oesophageal manometry in patients with non-cardiac chest pain. Gut 1988; 29: 1029-34.

4 Kjellin G, Tibbling L. Oesophageal motility during acid provoked heartburn and chest pain. Scand $\mathcal{F}$ Gastroentero 1985; 20: 937-40.

5 Hewson EG, Sinclair JW, Dalton CB, Wu WC, Castell DO, Richter JE. Acid perfusion test: Does it have a role in the
assessment of non-cardiac chest pain? Gut 1989; 30: 305-10.

6 Tuttle SG, Bettarello A, Grossman MI. Esophageal acid perfusion test and a gastroesophageal reflux test in patients with esophagitis. Gastroenterology 1960; 38: 861-72.

7 Siegel CI, Hendrix TR. Esophageal motor abnormalities induced by acid perfusion in patients with heartburn. $\mathcal{F} \mathrm{Clin}$ Invest 1963; 42: 686-95.

8 Bennett JR, Atkinson M. Oesophageal acid perfusion in the diagnosis of precordial pain. Lancet 1966; ii: 1150-2.

9 Skinner DB, Booth DJ. Assessment of distal esophageal function in patients with hiatal hernia and/or gastroesophafunction in patients with hiatal hernia and
geal reflux. Ann Surg 1970; 172: 627-37.

10 Benz LJ, Hootkin LA, Marguiles S, Donner MW, Cauthorne RT, Hendrix TR. A comparison of clinical measurements of RT, Hendrix TR. A comparison of clinical measurements

11 Sladen GE, Riddell RH, Willoughby JMT. Oesophagoscopy, biopsy, and acid perfusion test in diagnosis of "reflux" oesophagitis. $B M F$ 1975; 1: 71-6.

12 Behar J, Biancani P, Sheahan DG. Evaluation of esophagea ests in the diagnosis of reflux esophagitis. Gastroenterolog 1976; 71: 9-15.

13 Breen KJ, Whelan G. The diagnosis of reflux oesophagitis: An evaluation of five investigative procedures. Aust NZ F Surg 1978; 49: 156-61.

14 Kaul B, Petersen H, Grette K, Myrvold HE, Halvorsen T. The acid perfusion test in gastroesophageal reflux disease. Scand f Gastroenterol 1986; 21: 93-6.

$15 \mathrm{De}$ Caestecker JS. Twenty-four-hour $\mathrm{pH}$ monitoring: advances and controversies. NF Med 1989; 34: S20-S39.

16 Department of Clinical Epidemiology and Biostatistics University Health Centre. How to read clinical journals. II To learn about a diagnostic test. Can Med Assoc F 1981; 124: 703-10.

17 Simel DL. Playing the odds. Lancet 1985; i: 329-30.

18 Wienbeck M, Berges W. Esophagel disorders in the etiology 
and pathophysiology of dyspepsia. Scand $\mathcal{f}$ Gastroenterol (Suppl 109) 1985; 109: 133-43.

19 Palmer ED. The hiatus hernia-esophagitis-esophageal stricture complex. Am $₹$ Med 1968; 44: 566-79.

20 Heading RC, Blackwell JN, Cameron EWJ. Long term management of reflux patients. In: Cimetidine in the $80 \mathrm{~s}$. Ed J H Baron. Churchill Livingstone 1981: 172-80.

21 DeMeester TR, Wang CI, Wernley JA, et al. Technique indications and clinical use of 24 hour esophageal $\mathrm{pH}$ monitoring. $\mathcal{F}$ Thorac Cardiovasc Surg 1980; 79: 656-67.

22 Schindlbeck NE, Heinrich C, Konig A, Dendorfer A, Pace F, Muller-Lissner SA. Optimal thresholds, sensitivity and specificity of long-term $\mathrm{pH}$-metry for the detection of gastroesophageal reflux. Gastroenterology 1987; 93: 85-90.

23 Knill-Jones RP, Card WI, Crean GP, James WB, Spiegelhalter DJ. The symptoms of gastro-oesophageal reflux and of oesophagitis. Scand $\mathcal{F}$ Gastroenterology 1984; 19 (suppl 106): oesop.

24 Johansson KE, Boeryd B, Johansson K, Tibbling L. Doubleblind crossover study of ranitidine and placebo in gastro- esophageal reflux disease. Scand $\mathcal{F}$ Gastroenterol 1986; 21: 769-78

25 Howard PJ, Pryde A, Heading RC. Acid exposure times do not identify patients with symptomatic gastro-oesophageal reflux. Clinical Science 1989; 76 (suppl 20); 40P.

26 Janssens J, Vantrappen G, Ghillebert G. 24-hour recording of esophageal pressure and $\mathrm{pH}$ in patients with noncardiac chest pain. Gastroenterology 1986; 90: 1978-84.

27 Richter JE, Barish CF, Castell DO. Abnormal sensory perception in patients with oesophageal chest pain. Gastroenterology 1986; 91: 845-52.

28 Vantrappen G, Janssens G, Ghillbert G. The irritable oesophagus - a frequent cause of angina-like pain. Lancet 1987; i: 1232.

29 Peters LF, Petty DA, Wu WC, Castell DO. Spontaneous noncardiac chest pain: evaluation by 24 -hour ambulatory esophageal motility and $\mathrm{pH}$ monitoring. Gastroenterology 1988; $94: 878-86$.

30 Tuttle SG, Ruffin F, Bettarello A. The physiology of heartburn. Ann Intern Med 1961; 55: 292-300. 